\title{
El Tiempo en "Las Ruinas Circulares" de Jorge Luis Borges
}

\section{Tiempo de la lectura y tiempo imaginario}

Leer un cuento es como escuchar una melodía: las notas o las palabras van desplegando una unidad sucesiva cuya forma queda perfecta sólo al terminar la sucesión; la aprehensión de la forma se desarrolla en un intervalo, en este caso el tiempo de la lectura, especie de presente suspendido en el tiempo de la realidad cotidiana. ${ }^{1}$

Mientras dura este presente el lector se sumerge en otro tiempo, el del mundo creado por la narración; este es el tiempo al que voy a referirme aqui, el tiempo imaginario de "Las ruinas circulares", en el que un hombre se propone y consigue soñar otro hombre, interpolarlo en la realidad, pero finalmente descubre que también él es soñado por alguien.

En "Las ruinas circulares" el tiempo es, aparentemente, lineal, pues el orden de la narración parece seguir el orden en que los acontecimientos ocurren, acontecimientos que pueden reducirse a la alternancia de sueño y vigilia, mientras el hombre trata de llevar a cabo su proyecto. El tiempo de la narración comienza a transcurrir "en la unánime noche", cuando el hombre desembarca cerca de un templo en ruinas; no hay en este hombre ninguna huella de pasado, pues el proyecto fantástico "ha llenado el espacio entero de su alma", de modo que el tiempo no existe antes para él. A partir de entonces la narración sigue un curso en apariencia minucioso, que sugiere al lector la exigencia de un esquema temporal estricto; sin embargo, sólo habrá una larga sucesión de noches y

1 Husserl, E., The Pheonomenology of Internal Time-Consciousness (Bloomington and London, Indiana University Press, 1966), p. 41: "Thus; for example, a discrete succession can be held together without prejudice to the lack of simultaneity of its members through a bond of consciousness, through a unitary apprehension. That several successive tones yield a melody is possible only in this way, that the succession of psychical processes are united 'forthwith' in a common structure." 
crepúsculos, que a veces se agruparán en fragmentos de tiempo sin nin. guna conexión con el todo (nueve o diez noches, luego otras catorce); progresivamente se irán acumulando, casi implacables pero siempre cuidadosamente, en meses, años y lustros. Los minuciosos datos de la narración que pretenden organizarlo, hacen aún más evidente y casi dolorosa la existencia del tiempo, y el lector lo siente como un camino necesario pero difícil de recorrer.

Sueño y vigilia se suceden alternativamente "hacia medianoche", "al principio... poco después", "a las nueve o diez noches", "una tarde", "toda esa noche y todo el día", como tiempo en el que transcurre el proyecto del mago de soñar un hombre. Hacia el final del cuento el mago comprende que también él es un sueño: cuando se incendian las ruinas del templo que forma su mundo y el fuego no lo quema, se da cuenta entonces de su condición de fantasma. Pero esto es, lo sabemos entonces, una repetición de "lo acontecido hace muchos siglos". El hombre, que es sólo un sueño, seguitá existiendo mientras alguien siga soñándolo, evidentemente ha seguido existiendo ya antes; el olvido, que es un modo de reducir el tiempo a la nada, le permitirá volver a recorrer el mismo tiempo otra vez, volverá a desembarcar "en la unánime noche" para volver a soñar un hombre.

La sucesión de noches inumerables, la línea temporal progresiva en apariencia, se vuelve ahora sobre sí misma, forma un círculo que encierra todo el curso temporal recorrido, y crea además infinitos círculos de soñadores y soñados. La "unánime noche", que era el punto de partida del tiempo imaginario, se convierte ahora en el mundo temporal y espacial donde los infinitos soñadores describirán, o han descrito, infinitos círculos de sueños.

La forma queda así perfecta, como después de la última nota de una melodía. Y ya fuera de la lectura, en mi mundo temporal de mi realidad cotidiana, puedo preguntarme si yo, que he imaginado (tan parecido a soñar) a un hombre que era, sin saberlo, sueño de otro, no he recorrido sin saberlo un círculo más en ese juego inquietante de círculos infinitos.

El círculo es una de las figuras más usadas por poetas y filósofos para definir la eternidad, y a Dios; sólo que esta forma toma diferentes sentidos según la concepción de diferentes épocas y autores. ${ }^{2}$ "Las ruinas circulares" usa la misma metáfora para dar también una intuición de la

${ }^{2}$ Poulet, G., Les métamorphoses du cercle (Paris, Plon, 1961), Avantpropos: "Par 'métamorphoses du cercle' il faut donc entendre ici non les métamorphoses d'une forme par définition non-métamorphosable, mais les changements de sens, auxquels elle n'a cessé de se prêter dans l'esprit humain." 
eternidad, ahora como repetición infinita y simultánea de círculos ya recorridos y ya olvidados, ya reducidos a la nada. Sobre la concepción de Dios, quizá el soñador máximo en "Las ruinas circulares", creo que la respuesta está en la primera oración del texto: "Nadie lo vio desembarcar en la unánime noche, nadie $[\ldots]$ : un mundo aún más aterrador que el de Pascal".

$\mathrm{Si}_{\mathrm{i}}$ reducimos Dios a nadie, podemos establecer una relación entre la concepción de la eternidad del círculo en Pascal y la de Borges en "Las ruinas circulares", lo cual equivaldría, en cierto modo, a establecer una relación entre dos épocas. ${ }^{3}$ Con algunas diferencias, la imagen de Pascal ${ }^{4}$ del hombre dormido que desembarca en una isla desierta puede haber influido en la imagen de este otro hombre soñado.

\section{ANálisis de intuiciones, de significantes Y de Significados}

La constitución del tiempo, imaginario o real, supone, por una parte, la duración en el curso del tiempo; por otra parte, la disposición u orden de las frases de esa duración, y los puntos que determinan ese orden. ${ }^{5}$

${ }^{3}$ Id. ibid., p. 56: "Aussi, lorsqu'après tant de penseurs, Pascal reprend la fameuse phrase: 'C'est une sphère infinie dont le centre est partout, la circonférence nulle part', il est hors de doute qu'il 'emploie dans un sens très différent de celui que lui avaient conféré ces penseurs. Loin de formuler une conception objective de Dieu, elle exprime ici la conception la plus rigoureusement subjective d'un unvers qu'n ne peut imaginer sans en voir s'évanouir a partir du point central où on l'imagine, la péripherie dans la distance; de sorte qu'entre lui et soi on ne peut trouver de proportions."

4 Pascal, B., Copie des pensées, p. 646 (citado por Poulet): "En voyant l' aveuglement et la misère de l'homme, en regardant l'univers muet $[\ldots]$, j'entre en effroi comme un homme qu'on aurait porté endormi dans un île déserte et effroyable, et qui s'éveillerait sans connaître où il est, et sans moyen d'en sortir."

En su ensayo "La esfera de Pascal" (Otras inquisiciones, Buenos Aires, Emecé, 1960, pp. 13-17), Borges se refiere a la comparación que Pascal hace entre el hombre y un náufrago en una isla desierta [p. 16]; posiblemente sea este el pasaje del que habla.

${ }_{5}$ Husserl, E., ob. cit., p. 109: "Consequently, like two aspects of one and the same thing, there are in the unique flux of consciousness two inseparable, homogeneous intentionalities which require one another and are interwoven with one another. By means of the one, immanent time constituted, i.e., an Objective time, an authentic time in which there is duration and alteration of that which endures. In the other is constituted the quasi temporal disposition of the phases of the flux, which ever and necessarily has the flowing now-point, the phase of actuality, and the series of preactual and post-actual (of the not yet actual) phases." 


\subsection{Duraciones}

Al terminar la lectura de "Las ruinas circulares", la forma del ticmpo imaginario recorrido se cierra en un círculo que une al final del cuento con su principio: el hombre, que por fin comprende "en un alba sin pájaros" que es sólo un sueño de otro, desembarcará nuevamente "en la unánime noche" para volver a soñar un hombre.

El círculo de tiempo imaginario trazado por la narración no está sin embargo completamente cerrado; entre el "alba sin pájaros", cuando se repite "el incendio acontecido hace muchos siglos", y la "unánime noche" inicial, hay un espacio temporal lleno de olvido, pues al desembarcar el mago con el proyecto de soñar un hombre ya ese proyecto "había agotado el espacio entero de su alma; si alguien le hubiera preguntado su propio nombre o cualquier rasgo de su vida anterior, no habría acertado a responder." ( $R C$, p. 60) Corresponde al lector cerrar el círculo, llenar el intervalo entre "el alba sin pájaros" y "la unánime noche", aparentemente con las horas que en la realidad cotidiana pueden existir entre el alba y la noche, o bien con los "muchos siglos" que la narración crea entre las repeticiones del ciclo ("porque se repitió lo acontecido hace muchos siglos"), o con el olvido, el tiempo abolido que al comienzo del tiempo llena "el espacio entero" del alma del mago.

Cuando el lector cierra el círculo, se manifiesta el dinamismo de la forma: la duración comprendida en el transcurso de la narración, la serie de noches y crepúsculos, se dilata en una duración infinita donde el vacío del olvido (el espacio temporal entre "el alba sin pájaros" y "la unánime noche") es siempre mayor que el tiempo imaginario realmente transcurrido; y ese círculo que casi vibra al dilatarse y contraerse alternativamente, se multiplica a la vez en una infinita repetición de círculos de sueños, de soñadores y soñados; "la unánime noche" inicial es ahora el círculo que contiene a todos los otros, es el mundo espacial y temporal de la simultaneidad de duraciones; en una palabra, es la eternidad, el nunc stans.

El curso de la narración consigue así crear una duración del tiempo imaginario en continua y oscilante ambigüedad; el lector intuye la eternidad por la duración del olvido en cada trazado circular; en la duración secular de cada intervalo entre los ciclos; en la simultaneidad espacial y temporal de las duraciones de todos los círculos "en la unánime noche".

La imagen final de duración de tiempo imaginario se va constituyendo a través de la narración con imágenes de duraciones parciales que tienden todas a un mismo sentido, la duración de la eternidad. 
La primera intuición de tiempo que el texto evoca es: "Nadie lo vio desembarcar en la unánime noche [...]", hito temporal con valor de puntualización si considero el texto en la perspectiva lineal progresiva de la lectura: el tiempo imaginario empieza a transcurrir en esa "unánime noche" cuando el hombre desembarca para llegar al templo en ruinas y realizar su proyecto de soñar un hombre; pero en la perspectiva total desde el final del cuento esa misma noche toma también otro valor, es ahora, además, la duración total que resume en sí la pluralidad de noches y crepúsculos, de meses, años, lustros, siglos y ciclos que la narración ha ido desplegando.

A partir de esa noche y en verdad en esa noche, las imágenes de duraciones parciales ocurren, evocadas por palabras cuya significación se refiere a un mundo objetivo temporal (día, noche, tarde, crepúsculo, alba); o bien por relaciones internas del texto que confieren valor tenporal a palabras que ordinariamente no lo tienen (sueño, vigilia); a bien por relaciones internas entre las imágenes en el movimiento general de la narración.

"Día" y "noche" son las palabras con significado de duración temporal que se repiten casi rítmicamente en el curso de la narración; ya en las primeras líneas del texto aparecen "noche" y "día" con el valor que tendrán en el tiempo imaginario del cuento: "Nadie lo vio desembarcar en la unánime noche, nadie vio la canoa de bambú sumiéndose en el fango sagrado, pero a los pocos días nadie ignoraba que el hombre taciturno venía del Sur $[\ldots]$ " (RC, p. 59).

"Noche" y "día" no forman aquí una oposición equivalente a la de luz-oscuridad; "días" no corresponde en el texto al tiempo de luz y sol, sino que tiene el valor de una unidad de duración en la que están comprendidos día y noche, la luz y también la oscuridad. Nunca, en el transcurso del texto, "día" hará referencia a luz:

"Con el pretexto de la necesidad pedagógica, dilataba cada día las horas dedicadas al sueño $[\ldots]$ " (RC, p. 64).

"En general sus dias eran felices [...]" [p. 64].

"El hombre, un dia, emergió del sueño como de un desierto viscoso, miró la vana luz de la tarde [...]" [p. 61].

"logró dormir un trecho razonable del día [...]" [p. 62]. Una vez "noche" y "día" están usadas en aparente oposición:

"Toda esa noche y todo el día, la intolerable lucidez del insomnio se abatió sobre él." [p. 61]. 
Pero la apatente oposición también puede aquí ser interpretada, por el cambio de los determinantes (esa noche, el día), como una relación de inclusión: en este sentido, el día como duración envuelve e incluye a la noche; esta será la imagen que "día" evoca en el texto; y aún más, la única manifestación de día suele ser, en las imágenes evocadas por la narración, la noche o la zona intermedia de los crepúsculos. ${ }^{6}$ El final del cuento revela sin embargo la mera apariencia de esta imagen, pues "la unánime noche" envuelve finalmente la también aparente sucesión de noches o crepúsculos (o de los días que los incluyen).

Desde el punto de vista del significante, la casi rítmica sucesión de días y noches se refleja también en el tiempo de la lectura por la repetición de palabras o de construcciones sintácticas:

[...] sabía que ese templo era el lugar que requería su invencible propósito; sabía que los árboles incesantes no habían logrado estrangular, río abajo, las ruinas de otro templo propicio $[\ldots . .$.$] "$ [p. 60].

"Queria soñar un hombre: quería soñarlo [....]" [p. 60].

"Una tarde (ahora también las tardes eran tributarias del sueño; ahora […]" [p. 61].

"Comprendió que el empeño de modelar la materia incoherente [.:-.. Comprendió que un fracaso inicial era inevitable." [p. 62].

El día, que incluye las noches, es la duración de tiempo objetivo, cósmico, cuya alternancia confiere un ritmo a la narración y crea el mundo objetivo donde el mago existe.

En el tiempo del mago, la alternancia que toma valor de duración temporal es la de sueño y vigilia: "el hombre, en el sueño y en la vigilia, consideraba las respuestas de sus fantasmas [...]" [p. 61].

Día, en la duración objetiva del mundo de la naturaleza; sueño y vigilia, en la duración del tiempo del mago. Estas dos duraciones no se corresponden de la manera a la que la realidad cotidiana nos ha habituado: esperatiamos que "día" correspendiera a "vigilia", "noche" a "sueño"; la vigilia, por lo tanto, incluiría, y quizá determinaría, nuestro

6 V. Barrenechea, Ana María, La expresión de la irrealidad en la obra de Jorge Luis Borges (México, El Colegio de México, 1957), p. 97: "Al comentar la poesía de González Lanuza explica claramente lo que las puestas de sol significan para él: la unión de una infinitud espacial y de una angustia temporal." 
sueño. Pero el tiempo imaginario de sueño invade progresivamente, en el transcurso de la narración, al tiempo de vigilia:

"[...] (ahora también las tardes eran tributarias del sueño, ahora no velaba sino un par de horas al amanecer) [...]": [p. 61].

"[...] dilataba cada día las horas dedicadas al sueño [...]" [p. 64].

Hay por lo tanto falta de correspondencia entre el ritmo de nuestra realidad cotidiana y el ritmo de este tiempo imaginario.

Asi como la aparente oposición, o la aparente inclusión de la noche en el día como duración objetiva se revela al final del cuento como mera apariencia, pues la "unánime noche" envuelve la sucesión engañosa d: días, también la oposición de sueño y vigilia resulta engañosa cuando al final del cuento la vigilia se revela como falsa proyección del tiempo de sueño.

La relación entre estas dos duraciones, día-vigilia y noche-sueño, que existe en la realidad cotidiana de la que partimos como lectores, se va alterando en el curso del tiempo imaginario creado por la narración: los días terminan por quedar incluidos en "la unánime noche", y el tiempo de sueño va invadiendo el tiempo de vigilia hasta que el día se convierte casi en su totalidad en tiempo de sueño. Finalmente, así como los días son una falsa proyección de "la unánime noche", también el tiempo de vigilia, en la duración humana, es una falsa proyección del tiempo de sueño, pues lo que el mago cree su vida es sólo el sueño de otro.

La duración que el lector imagina está representada por lo tanto en un doble nivel: duración humana y duración objetiva, reducidas cada una a sueño y noche.

El mundo objetivo imaginario aparece proyectado también en los sueños del mago:

"[...] el anfiteatro circular que era de algún modo el templo
incendiado." [p. 60]. Ya no hay, en esta proyección soñada del mundo objetivo, una sucesión de noches y crepúsculos: los alumnos que el mago sueña están en las gradas del anfiteatro, las caras de los últimos "a siglos de distancia"; está representado así, en la duración del tiempo de sueño, un tiempo objetivo especializado, como simultaneidad de siglos o simultaneidad de 
las duraciones del tiempo humano. Esta imagen, aceptada por el lector como imaginariamente irreal, pues es sólo un sueño del mago, se impone luego al mundo objetivo del cuento, cuando el mago se da cuenta de que es un fantasma: entre soñador y soñado coexisten efectivamente siglos de distancia; la "unánime noche". del comienzo, en apariencia punto de partida de la duración temporal, se conviette finalmente en el círculo total de duración del único tiempo real imaginario, la duración del tiempo de sueño.

\subsection{Puntos temporales}

Los hitos temporales van marcando, durante la narración, las duraciones parciales del tiempo objetivo en las que aparentemente se inserta la duración del tiempo humano: vigilia y sueño.

El curso del tiempo se inicia "en la unánime noche". A partir de este punto, el próximo hito temporal es "a los pocos días", cuando ya "nadie ignoraba" de dónde ha llegado el mago. El intervalo delimitado por estos dos puntos parece, a primera vista, perfectamente preciso: "pocos" indica un cuidado minucioso del narrador por marcar el tiempo objetivo inaginario; sólo más adelante, cuando el lector comienza a sentir el tiempo como tropiezos en su intento de organizarlo, ve en la reticencia de "pocos días" un falso detalle que sólo se propone frenar el libre correr del tiempo.

El siguiente punto corresponde también al tiempo objetivo de la naturaleza: el hombre, después de desembarcar, llega hasta el templo, se tiende bajo el pedestal, y "lo despertó el sol alto".

Dos líneas temporales parten de la "unánime noche", superponiéndose sin coincidir completamente: la primera, que lleva hasta "pocos días" después, señala el tiempo compartido entre el forastero y los habitantes de la región, y comienza a integrar al hombre recién llegado en un mundo humano, pero esa integración, y la línea temporal que la mar$\mathrm{ca}$, quedan allí truncas; la segunda línea recorre el trayecto de tiempo desde la noche hasta "el sol alto", integra al hombre en el mundo de la naturaleza e inicia el ritmo del curso temporal objetivo de la narración, la larga serie de días. Estas dos líneas, parcialmente superpuestas pero divergentes, confunden ya en el comienzo el trazado del tiempo por la parcial coincidencia entre ambas y por la disimulada vaguedad en la delimitación de cada una de ellas.

Todos los hitos temporales señalados en el transcurso de la narra- 
ción tienen la misma aparente precisión y la misma real ausencia de claridad; el resultado es un tiempo imaginario tan elusivo y dificil que es imposible dejar de sentirlo casi como si tuviera consistencia de materia.

Puntos de prolija vaguedad son los que marcan los intervalos de duración en los primeros intentos del mago de soñar un hombre: "bacia la medianoche", "al principio... poco después". Hay sin embargo un periodo cuyos límites están marcados con claridad:

"A las nueve o diez noches comprendió con alguna amargura $[\ldots]$ [p. 61].

Pero la exactitud está negada por la vacilación entre nueve $o$ diez; y aun cuando el número fuera decididamente claro, la falta de relación entre este intervalo y el todo lo presenta como un fragmento inconexo, perdido en la duración.

"Una tarde",... "un día", "un dia", son las delimitaciones temporales en el progreso de los intentos del mago. No hay además ninguna construcción sintáctica que convierta alguna significación en circunstancia temporal.

Cuando el primer período de ensayos fracasa, el mago "juró olvidar la enorme alucinación que lo había desviado al principio y buscó otro método de trabajo." [p. 62].

El comienzo del segundo intento tiene indicaciones de puntos temporales igualmente confusos:

"Antes de ejercitarlo, dedicó un mes a la reposición de las fuerzas que había malgastado el delirio. Abandonó toda premeditación de soñar y casi acto continuo logró dormir un trecho razonable del día. Las raras veces que soñó durante ese periodo, no reparó en los sueños. Para reanudar la tarea, esperó que el disco de la luna fuera perfecto. Luego, en la tarde, se purificó en las aguas del río, adoró los dioses planetarios, pronunció las sílabas lícitas de un nombre poderoso y durmió. Casi inmediatamente, soñó con un corazón que latía." [p. 62].

El tiempo tiene aquí límites marcados de tal modo que se deslizan tan pronto como la conciencia intenta captarlos, pues se confunden el mes que el mago dedica a la reposición de fuerzas y el mes lunar que deja transcurrir para reanudar la tarea; sólo quedan más o menos claramente delimitados "una tarde" y "un trecho razonable del día".

También en esta segunda etapa de ensayos hay un periodo definido:

[...] "con minucioso amor lo soñó durante catorce lúcidas noches." [p. 62]. 
Catorce noches exactas que hacen sentir aún más agudamente el tiempo cuidadosamente dibujado que las rodea. Después de esas catorce noches, otra vez los límites imprecisos y reticentes:

"Antes de un año llegó al esqueleto $[\ldots] "$ [p. 63].

Las noches que pasan incesantes en el transcurso de la nartación se acumulan ya, con la misma cuidadosa vaguedad: "antes de un año" es casi un año de noches, pero no alcanzan al límite marcado; siempre el tiempo marcado es mayor que el tiempo realmente transcurrido.

Los puntos del progreso temporal están a veces señalados por la presencia de verbos, que crean tiempo al dar imágenes de movimiento. Cuando el mago termina de soñar "un hombre íntegro", quizá en catorce noches exactas, quizá "antes de un año", pues los dos periodos están señalados en la narración.

"Una tarde, el hombre casi destruyó toda su obra, pero se arrepintió." [p. 63].

"Ese crepúsculo" pide ayuda al dios de las ruinas circulares. Entre "una tarde" y "ese crepúsculo", que pueden ser en realidad el mismo límite de tiempo, hay sin embargo tiempo creado por una serie de verbos:

"Agotados los votos a los númenes de la tierra y del río, se arrojó a los pies de la efigie, que tal vez era un tigre y tal vez un potro, e imploró su desconocido socorro." [p. 63].

El movimiento en el espacio es mínimo: "era" evoca tiempo anterior por medio de una imagen estática, "imploró" representa en todo caso una imagen de movimiento interior, y el reflexivo "se arrojö" significa una acción que vuelve hacia el sujeto; se crea así un tiempo de mera apariencia, la ilusión de un periodo entre dos puntos que son en realidad uno (la tarde y el crepúsculo).

Finalmente, el mago consigue, con ayuda del dios, interpolar a su hijo en la "realidad", y se dedica a instruirlo para que pueda vivir en ella. Este periodo de aprendizaje, que "abarcó finalmente dos años", está también marcado por puntos imprecisos: "una vez", "al otro día", "cada vez", "esa noche". El mago "persiste en una suerte de éxtasis" cuando su hijo parte hacia el otro templo; esto parece indicar que el tiempo de sueño ha terminado, y que padre e hijo se instalan en la realidad de la vigilia. 
Todos los puntos temporales que hasta aquí han ido señalando la duración de los sueños sólo marcan fragmentos inconexos o puntos aislados en la duración.

Casi al final de la narración, el mago teme por ese hijo "pensado" (no se dice ya "soñado") en "mil y una noches secretas"; quizá los vagos puntos que señalaban el curso temporal abarcan, en fin, mil y una noches; pero la remisión al tiempo mítico en ese número de tan fácil referencia a la literatura, y la resonancia del uso coloquial en el que "mil y una" significa simplemente "muchas", le quitan exactitud y verosimilitud; por otra parte, es ésta una afirmación del narrador, fuera del mundo mimético: "Es natural", dice el narrador, "que el mago temiera por el porvenir de aquel hijo, pensado entraña por entraña y rasgo por rasgo, en mil y una noches secretas." [p. 65].

El próximo segmento temporal está limitado por:

"Al cabo de un tiempo que ciertos narradores de su historia prefieren computar en años y otros en lustros, lo despertaron dos remeros a medianoche: $[\ldots] "$ [p. 65].

Los mismos límites imprecisos, confundidos además por la diversidad de medidas: años, o lustros; "a medianoche" es, dentro de este periodo impreciso, un punto temporal de ilusoria exactitud.

Una rápida sucesión de líneas temporales sucesivas llevan al término del tiempo en la narración:

"Primero (al cabo de una larga sequía) una remota nube en un cerro, liviana como un pájaro; luego, hacia el Sur, el cielo que tenía el color rosado de la encía de los leopardos; luego las humaredas que herrumbraron el metal de las noches; después la fuga pánica de las bestias." [p. 66].

La ausencia de verbos en las proposiciones regentes, y la presencia de sustantivos que evocan imágenes dinámicas, hacen que el curso del tiempo adquiera una vibración de movimiento detenido, en el que sin embargo como en un remanso se siente su persistencia y morosidad; "la fuga pánica de las bestias" contribuye, con la sustantivación del movimiento, a la intuición de tiempo contenido en estados, de tiempo que dura, en puntos dilatados por esa duración.

Se repite entonces "lo acontecido hace muchos siglos", el fuego invade nuevamente las ruinas circulares: hay aqui un último hito temporal objetivo: 
"En un alba sin pájaros el mago vio cernirse contra los muros el incendio concéntrico." [p. 66].

Las imágenes que crean tiempo objetivo representan siempre los momentos de límites imprecisos en los que luz y oscuridad parecen invadirse mutuamente, representando así un continuo acontecer de la naturaleza. Paralelo a este tiempo objetivo, al "alba sin pájaros", sigue trascurriendo el tiempo humano: "por un instante" el mago cree que va a morir, cree asumir su condición de hombre; pero en ese instante, en el único punto del curso temporal que parece ofrecer un apoyo casi tangible, aunque inasible, al ser humano, el hombre vive una simple ilusión: "luego" comprende, cuando el fuego no lo quema, su condición de fantasma.

En resumen, los puntos temporales señalan en la duración objetiva límites indecisos, determinan segmentos de tiempo parcialmente superpuestos e inconexos. Por la confusión de las líneas, la forma del tiempo objetivo adquiere un movimiento a cuyo ritmo el tiempo humano de sueño y vigilia no corresponde con regularidad, creando así una falta de sincronización entre la duración objetiva y la duración humana y un múltiple dinamismo.

\subsection{Medidas}

Tiempo de sueño es la duración infinita creada por "Las ruinas circulares"; la aparente duración de los días, en el tiempo objetivo, se condensa (y se dilata a la vez), al final de la narración, en una sola "noche unánime" que es el mundo donde "ocurre" el sueño.

Las medidas que segmentan el tiempo objetivo imaginario lo dilatan ilusoriamente desde una aparente pluralidad de días hasta una sucesión cíclica de siglos; la condensación final en la unidad de la "unánime noche" que contiene todos los sueños y todos los tiempos permite una intuición de eternidad.

"Días" es la medida del tiempo imaginario propuesta desde el comienzo de la narración; esto confiere al tiempo, desde el principio, un movimiento de repetición cíclica que prefigura la concepción final de eternidad. Pero no son estos días los de nuestra realidad cotidiana: en este tiempo imaginario los días que se cuentan son sobre todo las zonas intermedias crepusculares; además, la medida humana del tiempo cronométrico no mide las horas de estos días, el sueño las mide, o las dilata. Cuando los días van acumulándose la perfección del disco de la luna 
señala en una ocasión el término de un periodo; pero la naturaleza no tiene, en este tiempo imaginario, más ciclo que el de los dias y su simple acumulación. El ciclo de las estaciones tampoco existe en el mundo de "Las ruinas circulares", a pesar de que los dias llegan a acumularse también en años; esta última medida tiene la misma ambigüedad que la de "día", pues la extensión de tiempo comprendida en un año, aun en nuestra realidad cotidiana puede variar hasta llegar a incluir cualquier número de días según sea el año lunar, solar, sideral, etc.

La medida con que según el narrador "ciertos narradores" computan el tiempo en la historia del mago varía de años a lustros; aunque extraña al mundo creado en el cuento esta observación del narrador pone en evidencia la relatividad de las medidas y la ilusoria dilatación del tiempo medido.

La narración traza hacia el final líneas de duración indefinida, para preparar una inesperada extensión de la medida del tiempo a siglos; aun medido en siglos, el tiempo sigue sin embargo transcurriendo de crepúsculo a crepúsculo.

Cuando los días constituyen la unidad de tiempo en la narración, la referencia a horas les da ilusoria profundidad de duración; cuando la unidad se dilata en siglos, el contraste violento con el instante crea la perspectiva de duración de la eternidad, al contraponer lo infinitamente pequeño con lo infinitamente extenso.

\subsection{Orden temporal}

La narración sigue en "Las ruinas circulares", el orden que aparentemente corresponde a los acontecimientos; el texto conduce prolija y progresivamente a la representación de un orden temporal imaginario en el que indudablemente existe un "antes" y un "después". Pero en el desenlace del cuento, cuando el mago comprende que es sólo un sueño de otro, la línea temporal progresiva cambia de dirección, se vuelve sobre sí misma para tender a cerrarse en círculo: si el mago que sueña otro hombre es a la vez sueño de alguien; si el incendio concéntrico es repetición de lo ocurrido hace muchos siglos; si por su condición de fantasma el mago puede hollar el fuego sin quemarse y seguirá por lo tanto existiendo mientras haya quien lo sueñe; entonces otra vez, otras veces, volverá a repetirse el ciclo, ya está repitiéndose, pues el hombre soñado por el mago, ya separado de él por el olvido, está también describiendo el mismo círculo. Y'a no hay, por lo tanto, un curso progresivo y lineal 
de los acontecimientos, el ordenamiento de anterioridad y posterioridad era sólo aparente: la verdad es la coexistencia de círculos de sueños en la eternidad de esa "noche unánime".

En el curso de la narración, el aparente orden temporal imaginario que el lector representa no es siempre claramente progresivo y lineal: a veces el narrador vuelve a trazar una línea temporal; otras veces, traza lineas divergentes y coexistentes en el tiempo. El resultado es una curva regresiva en el orden, de pretendida exactitud:

"Antes de un año llegó al esqueleto, a los párpados." [p. 63]

donde el tiempo trascurrido llega a un punto anterior al límite propuesto por la medida de un año; esto obliga a la imaginación a un doble movimiento en la línea temporal. La misma curva regresiva aparece otras veces:

"esa noche lo besó por primera vez y lo envió al otro templo [...] Antes (para que no supiera nunca que era un fantasma, para que se creyera un hombre como los otros) le infundió el olvido total de sus años de aprendizaje". [p. 64]

Las complicaciones en el ordenamiento temporal consiguen hacer sentir la dificultad del tiempo, pero también van preparando al lector para el movimiento regresivo final, en el que se confunden definitivamente anterioridades $\mathrm{y}$ posterioridades.

El orden temporal está expresado en la narración por el orden de los acontecimientos narrados, o por el uso de palabras que indican ese orden: "al principio $[\ldots]$ poco después"; "primero $[\ldots]$ luego $[\ldots]$ luego [...] después". Pero el uso de tiempos verbales es quizá el signo más importante que crea un ordenamiento en las representaciones temporales; en éstas, el eje fundamental y el punto de referencia están dados por el presente de la lectura, ${ }^{7}$ en la que lector y narrador son diferentes secuencias sincronizadas por el texto y por los signos de presente que en él aparecen.

En "Las ruinas circulares", el tiempo de la narración es el pasado: se sitúa la acción en un punto anterior al presente de lá lectura, con una

7 V. Bull, William E., Time, Tense, and the Verb (Berkeley and Los Angeles, University of California Press, 1960), p. 18: "The termination, then, though simultaneous with perception, is treated as anterior to the act of speak ing, and it is the initiation of speech wich serves as the axis of orientation, the point present, the PP of a tense system." 
perspectiva de alejamiento a la vez espacial y temporal. ${ }^{8}$ Ese tiempo anterior está completamente aislado del tiempo del lector, pues no hay ninguna referencia que los relacione.

Este es el tiempo principal de la narración; con respecto a ese pasado, hay un vector temporal de anterioridad dado por el uso del pluscuamperfecto y que indica un pasado inmediato anterior comprendido dentro del tiempo de la narración; esto contribuye a representar la duración del mundo objetivo: cuando el hombre, después de desembarcar, llega a las ruinas del templo,

"El forastero se tendió bajo el pedestal. Lo despertó el sol alto.

Comprobó $\sin$ asombro que las heridas habían cicatrizado; [...]" [p. 59]. El pluscuamperfecto se refiere aquí al vector temporal intermedio entre dos pasados: "se tendió [...] lo despertó", y "comprobó"; de esta manera la acción adquiere profundidad de duración temporal. Esta misma profundidad temporal referida al tiempo comprendido en la narración aparece representada cuando el hombre despierta por primera vez, a medianoche:

"Rastros de pies descalzos, unos higos y un cántaro le advirtieron que los hombres de la región habían espiado con respeto su sueño $[\cdots]$... [p. 60]; o en p. 61:

$[\cdots]$ "comprendió que no había soñado."

Pero el pluscuamperfecto establece además otro vector temporal, de un pasado anterior al tiempo total de la narración, que da aun una mayor profundidad temporal $y$ funda una existencia anterior del templo en ruinas:

"Sabía que los árboles incesantes no habían logrado estrangular, río abajo, la existencia de otro templo." [p. 59]

8 Bello en su Gramática, \$626, dice que este tiempo (pretérito) en los verbos desinentes "significa siempre la anterioridad de toda la duración del atributo al acto de la palabra [...]. Mas en los verbos permanentes sucede a veces que el pretérito denota la anterioridad de aquel solo instante en que el atributo ha llegado a su perfección: 'Dijo Dios, sea la luz, y la luz fue:' fue vale lo mismo que principió a tener una existencia perfecta." Ver, que es el primer verbo en "Las ruinas circulares", y está en pretérito, es, según Bello, verbo permanente, "porque la acción de ver es de aquellas que, perfectas, continúan durando". En \$692, Bello considera este pasado como "negación del presente". 
"Ese múltiple dios le reveló [...] que en ese templo circular (y en otros iguales) le habían rendido sacrificios y culto [...]" [p. 63].

El mago, por el contratio, comienza a existir cuando comienza a desplegarse el tiempo de la narración; por eso, la única vez que el pluscuamperfecto está usado para referirse a la existencia del mago anterior al tiempo de la narración, es para dar una resonancia anticipada del final del cuento:

"A veces, lo inquietaba una impresión de que ya todo eso había acontecido $[\cdots]$ " [p. 64].

Este valor del pluscuamperfecto crea una existencia anterior del mundo donde el mago existe, lo que coincide con el sentido general del cuento: el hombre es un sueño de alguien, el mundo parece preexistir a la multiplicidad de los sueños.

Las formas verbales usadas en la narración también tienden un vector temporal posterior al pasado de la narración, pero comprendido en ese pasado general; este futuro en el pasado tiene sin embargo siempre un matiz de posibilidad, a veces dado por el uso del subjuntivo:

"Le ordenó que una vez instruido en los ritos, lo enviara al otro templo $[\ldots]$ para que alguna voz lo glorificara $[\ldots]$ " [p. 64]

Una sola vez la forma verbal de futuro está usada por el mago mismo, pero el uso de "ahora" le confiere un valor de probabilidad:

"Abora estaré con mi bijo."

"El bijo que be engendrado me espera y no existirá si no voy"." [p. 64]

El futuro sólo existe aquí en la falsa perspectiva del personaje.

La narración emplea formas verbales que alejan espacial o temporalmente la acción del cuento con respecto al presente de la lectura; el uso

9 Gili y Gaya, Curso superior de sintaxis española (México, Minerva, 1943), p. 136, considera que el presente de indicativo, en oraciones condicionales, tiene valor de futuro. Para Bello (Gramática, $\$ 670$ ) ésta es una forma de indicativo prestada al subjuntivo hipotético: "Entonces, además de su valor primitivo, admite otro, en que el presente pasa a futuro, y co a pos: [...7." 
del presente, inesperado y asistemático en el texto, produce un brusco cambio de perspectiva, un acercamiento instantáneo que hace coincidir por momentos el tiempo del mundo narrado con el tiempo de la lectura. ${ }^{10}$ Este presente está ya usado en las primeras líneas del texto.

"[...] a los pocos días nadie ignoraba que el hombre taciturno venía del Sur, y que su patria era una de las infinitas aldeas que están aguas arriba, en el flanco violento de la montaña, donde el idioma zend no está contaminado de griego y donde es infrecuente la lepra." [p. 59]

El mundo objetivo, anterior a la existencia del mago, intersecta aquí el presente del lector: la aldea existe antes y después del mago, antes y después del presente del lector. Una de las finalidades que este uso asistemático del presente consigue es la verosimilitud, pues el mundo imaginado incide, por la coincidencia de presentes, en el nuestro; otra finalidad consiste en fundar la existencia absoluta del mundo objetivo imaginario. ${ }^{11}$

La misma forma verbal establece, en consecuencia, el presente absoluto en la existencia del templo:

"Ese redondel es un templo que devoraron los incendios antiguos, que la selva palúdica ha profanado y cuyo dios no recibe honor de los hombres." [p. 59],

donde el significado iterativo de "recibe" acentúa el valor de presente durativo que sobrepasa los límites del presente del lector. El templo, que es el mundo del mago, es acercado así a nuestro presente:

"Le ordenó que una vez instruido en los ritos, lo enviara al otro templo despedazado cuyas pirámides persisten aguas abajo, $[\ldots]$ " [p. 64]. [...] "y lo envió al otro templo cuyos despojos blanquean río abajo, [...]" [p. 64].

10 Bull (ob. cit.) considera que el presente de indicativo, cuando el sujeto es abstracto, tiene una significación de simultaneidad con respecto a todos los ejes de orientación: "the tense form, as a consequence, preserves only its value as imperfective aspect: [...] [p. 83]. Para Bello (Gramática, \$622) el presente de indicativo "significa la coexistencia del atributo con el momento en que proferimos el verbo"; pero en $\$ 623$ aclara que las dos duraciones pueden coexistir sólo parcialmente. También Gili y Gaya (ob. cit.) se refiere a este presente de acción continua, opuesto al de acción discontinua (presente histórico y habitual).

11 Bello (ob. cit.): "Por eso el presente es la forma que se emplea para expresar las verdades eternas o de una duración indefinida." [\$623] 
El presente verbal, referido al mundo objetivo imaginario, permite su coincidencia parcial en nuestro mundo real, y va preparando a la vez la imagen final de un mundo eternamente presente, en el que se repiten cíclicamente fragmentos del tiempo humano de sueño.

La eternidad, en una pura posibilidad, del tiempo humano, está significada por el infinitivo, sin determinación temporal ni personal. ${ }^{12}$

"No ser un hombre, ser la proyección del sueño de otro hombre, ¡qué humillación incomparable, qué véttigo! [p. 65]

Esta es la visión de la duración humana en la eternidad.

El narrador usa también la forma verbal de presente para salir dei mundo creado por la narración, y permitir al lector la perspectiva de los dos mundos, el imaginario y el de la realidad cotidiana:

"Lo cierto es que el hombre gris besó el fango [...]" [p. 59].

"En las cosmogonías gnósticas, los demiurgos amasan un rojo Adán que no logra ponerse de pie [...]" [p. 63]

"A todo padre le interesan los hijos que ha procreado $[\ldots]$ es natural que el mago temiera [...]" [p. 65]

"Comprendió que el empeño de modelar la materia incoherente y vertiginosa de que se componen los sueños es el más arduo que puede acometer un varón $[\ldots] "[$... 62]

El uso de estas formas verbales de presente establece, en todos los casos, una coincidencia con el tiempo del lector: algunas veces, el narrador lo usa para unir ambos mundos, el de la realidad cotidiana y el imaginario, con una afirmación de validez universal; otras veces acerca al lector el mundo imaginario objetivo (el templo circular que es el mundo del mago) para conferirle un valor temporal muy parecido a la eternidad, pues ese mundo es, está antes y después de la existencia del mago, antes, ahora y después del presente del lector.

El mago existe en una lejanía espacial y temporal; una vez, sus palabras restenan imaginariamente:

12 Bello, ob. cit., §420: "El infinitivo conserva el significado del verbo, despojado de las indicaciones de número y persona: si denota atributo, no es el del sujeto de la proposición; y si da algún indicio de tiempo, lo hace de otra manera que el verbo, como luego veremos." \$425: La proposición transformada así [con infinitivo en lugar de forma personal] deja de serlo en cuanto pierde su relación de tiempo con el acto de la palabra, como es propio de todas las proposiciones en castellano." 
"Ahora estaré con mi bijo." [p. 64]

"El bijo que be engendrado me espera y no existirá si no voy". [p. 64]

En el primer ejemplo, la forma verbal es de futuro; su combinación con otro signo de presente, "ahora", le confiere sin embargo un valor de simple probabilidad. En el segundo caso, la única forma verbal de presente en primera persona (la del mago) está en una subordinada, condicional y negativa, que deja a este presente también en un campo de pura posibilidad. [Ver nota 9]

El mago está siempre alejado del presente de la lectura, con un alejamiento muy semejante al que existe entre los alumnos del anfiteatro soñado por el mago.

En el mundo de "Las ruinas circulares" no hay futuro: ${ }^{13}$ la forma verbal de futuro sólo aparece en boca del mago, desde su perspectiva engañosa, pero con valor de posibilidad para la perspectiva del lector. Las otras formas verbales que tienden vectores hacia un futuro son formas de subjuntivo o de potencial, donde también aparece el matiz de posibilidad. No puede haber futuro en un mundo donde se repite lo ya acontecido "hace muchos siglos".

La eternidad de "Las ruinas circulares" es por lo tanto una eternidad hecha de pasado, un pasado ilusorio y olvidado que sigue siendo presente. La eternidad humana sólo existe como posibilidad de duración ilusoria de tragmentos aislados entre sí, como sueños inconexcs ya soñados. No hay un ordenamiento de anterioridad o posterioridad en este mundo imaginario; la posterioridad, como la presencia, es una mera ilusión.

\section{EL tIEMpo como sentido dE "LAS RUINas circulares"}

El tiempo fluye, en "Las ruinas circulares", como duración humana que trascurre en la duración objetiva. Sueño como duración humana, noche como duración objetiva, constituyen el tiempo del cuento.

Fragmentos inconexos y discontinuos forman el tiempo del mago, de tal manera que el tiempo para recorrer es más extenso que el tiempo recorrido: la existencia del hombre aparece finalmente como lo infinitamente

13 Barrenechea, Ana María, ob. cit., p. 107: "La idea de un pasado ilusorio o la suposición de que todo es pasado tienen mayor fuerza inventiva en su obra y resultan igualmente eficaces en la desintegración, porque si lo que recordamos haber vivido es sólo una creación de la mente, nada nos asegura que no lo sea también lo que vivimos ahora y al fin las dos proposiciones se reducen a la misma humillante comprobación de nuestra inanidad." 
pequeño dentro de la infinitud de la noche. Los puntos que marcan el progreso de la duración, imprecisos y confusos, determinan las medidas del tiempo: días, meses, años, lustros, siglos, se extienden hasta llegar a la medida absolutamente simple que es el infinito, el infinito de una noche y el del sueño.

El universo de noche y sueño se va armando a partir de un punto inicial en que el tiempo empieza a describir una forma que finalmente será circular y múltiple. El orden de la narración se disuelve en la recurrencia de círculos: donde ya todo ha ocurrido hay sólo un "antes", un pasado que vuelve a tomar la ilusoria apariencia de presente.

La duración humana es un fragmentado reflejo de la duración del sueño de otro; el mundo objetivo, la noche, es el espacio proyectado por el sueño. Los círculos no existen por lo tanto en un espacio exterior, sino en el espacio subjetivo creado por el sueño, o la conciencia, de otro soñador. Cualquier soñador recorre, desde un punto excéntrico, una circunferencia en parte borrada por el olvido, proyecta un punto en el espacio creado por su sueño, punto que a su vez, en un espacio ajeno, describe otra circunferencia y proyecta otro punto, indefinidamente. Hay, por lo tanto, un vértigo de círculos concéntricos cuyo centro, y también la circunferencia inicial, están en el infinito. La realidad existe más allá de la circunferencia de un sonador hipotético que envuelve a todas las otras, pero el movimiento de los círculos se aleja de ella. Infinito sin circunferencia hacia la realidad hipotética exterior, infinito sin centro hacia la realidad ilusoria interior, ésa es la eternidad de los círculos en "Las ruinas circulares".

El alivio, la humillación y el terror del mago cuando descubre que es sólo un sueño de alguien, no se debe a la angustia del tiempo, sino a la angustia de la eternidad: el mago acepta la muerte, y morir es salir del tiempo; lo que todavía no ha aceptado es que su tiempo sea una ilusión. Su falta de libertad no consiste en su sujeción al tiempo, sino en la falta de limites que pudiera traspasar.

El tiempo es, en "Las ruinas circulares", la imagen ilusoria de la eternidad, una imagen que se repite, fragmentada continuamente por el olvido.

University of California,

Marta Gallo Santa Bárbara. 